\title{
O DESGASTE DO TRABALHADOR DE ENFERMAGEM: RELAÇÃO TRABALHO DE ENFERMAGEM E SAÚDE DO TRABALHADOR
}

THE STRAINED PROCESS OF THE NURSING WORKERS:

THE RELATIONSHIP OF NURSING WORK AND NURSING HEALTH

EL DESGASTE DEL TRABAJADOR DE ENFERMERÍA: RELACIÓN ENTRE EL TRABAJO DE ENFERMERÍA Y EL TRABAJADOR DE DICHA ÁREA

\section{Vanda Elisa Felli da Silva ${ }^{1}$ \\ Paulina Kurcgant ${ }^{2}$ \\ Vilma Machado de Queiroz ${ }^{3}$}

RESUMO: O estudo busca a compreensão do processo saúde-doença, vivenciado pelos trabalhadores de enfermagem no desempenho de seu trabalho, fundamentado na determinação social desse processo. Evidencia as particularidades da relação trabalho-saúde de uma realidade concreta, decompondo e recompondo as intermediações processo de valorização, processo de trabalho, cargas de trabalho e desgaste, o que permitiu explicitar o perfil de morbidade desses trabalhadores. Nesse perfil, os ferimentos pérfuro-cortantes e as doenças ósteo-músculo-articulares aparecem como danos característicos desse grupo de trabalhadores de enfermagem.

PALAVRAS-CHAVE: Enfermagem, Saúde do trabalhador, Processo saúde-doença

ABSTRACT: The study aims the understanding of the process health-ilness, as it is experienced by nursing workers in the acting of its work, being bases in the social determination of that process. It evidences the particularities of the relationship between labor and health of a concrete reality. The adopted methodology permited to establish the link between the valorization process, work process, loads and strain. This relationship of determination permit to show the unhealthy profile of those nursing workers. The sharp accidents, bones, muscles and joint deseases are characteristics damages of in this profile.

KEYWORDS: Nursing, The worker's of nursing health, The health-ilness process

RESUMEN: El estudio busca la comprensión del proceso salud-enfermedad, vivenciado por los trabajadores de enfermería en el desempeño de su trabajo, fundamentado en la determinación social de ese proceso. Se evidencia las particularidades de la relación trabajo-salud de una realidad concreta, descomponiendo y recomponiendo las intermediaciones proceso de valorización, proceso de trabajo, cargas de trabajo y desgaste, lo que permitio explicitar el perfil de morbilidad de estos trabajadores. En este perfil, los accidentes pérfuro-cortantes y las enfermedades osteo-músculo-articulares aparecen como daños característicos en este grupo de trabajadores de enfermería.

PALABRAS CLAVE: Enfermería, Salud del trabajador, Proceso salud-enfermedad

1 Enfermeira. Prof ${ }^{a}$ Dr ${ }^{a}$ do Departamento de Orientação Profissional da Escola de Enfermagem da USP.

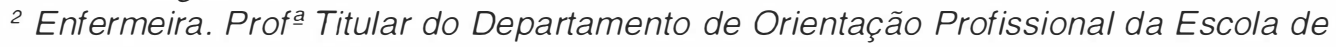
Enfermagem da USP.

${ }^{3}$ Enfermeira. Prof ${ }^{a}$ Dra do Departamento de Saúde Coletiva da Escola de Enfermagem da USP. 


\section{INTRODUÇÃO}

\subsection{A CONSTRUÇÃO DO OBJETO DE ESTULDO}

Nas duas últimas décadas, observamos $\left.u_{1}\right)$ increnentio de: publicações relacionados à saúde dos trabalhadores de enieıriayeın. Nc erıtanto, estas não são suficientes para caracterizar quanti-qualitativarnent : (0) problernas: específicos que emergem da relação entre trabalho de enfermą̧ $r$ e saúde dos triabalhadores.

A maioria dos estudos que abordam essiz temidica eshoorra nos limites do

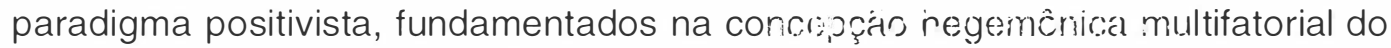
processo saúde-doença - PSD. Assim, registram a simiples ccorrêricia da doença e exploram os riscos ocupacionais como agentes existentes rio ambiente de

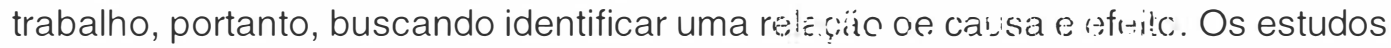
que buscaram ir além, ou não evidenciaram a génese no coletivo de trabalhadores ou não abarcaram a totalidade da relação trabalho de enfermagem e saúde dos trabalhadores.

Assim, propomos a realização dessa investigaçăoị Silva,1996), fundamentando-nos no referencial teórico-metúcúb́y.c:o operacicnai desenvolvido por Laurell; Noriega (1989), tomando como obj a!u de usiudo a relaçäo trabalhosaúde, expressa nos trabalhadores de enfernaçem de F'c spital Universitário da Universidade de São Paulo - HU-USP, em particulır

Essa relação expressa-se no corpo kickííquico dos trabalhadores de

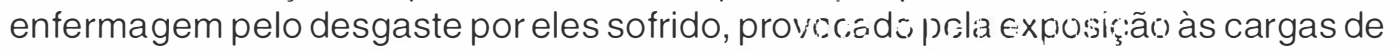
trabalho, geradas nos processos de trabalho, submotixos que estã () aos processos de valorização da produção em saúde na sociedacie cápiialista.

Esse objeto é resgatado do contexto social onde está inserido, isto é, da produção em saúde articulada ao setor terciáric) de produção, especificamente na prestação de serviços. Esse serviço institucionaızado é prestado em estabelecimentos hospitalares e não hospitalares, cnce as práticas de saúde, tanto do setor público como privado, são legitimadas pera po'ític a ciè siaúde, no contexto das políticas sociais. Essas práticas são executaưás $p \in$ la icrȩa de trabalho em saúde que operacionaliza a política de saúde.

Nesse contexto, buscamos apreender o irabuaihio eın saúcie articulando às demais práticas sociais e dessa articulação exträir $\in$ hicéćc quizar us determinantes do processo trabalho-saúde vivenciado em fartizlia: pelss trabalhadores de enfermagem.

Esse estudo, portanto, tem por objetivo eviúnr,ciar as frarticularidades da relação de determinação trabalho-saúde que se exp:-sş inos, trabalhadores de enfermagem do HU-USP, no desenvolvimento de se!. trạbalho.

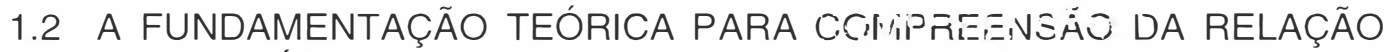 TRABALHO-SAÚDE}

Evidenciar como o trabalho gera processos saride-dherça implica em explicitar como o social se traduz no biológico e como esse se suhmete ao social, como é 
explicado por Laurell (1983).

O PSB enquanto processo coletivo e social que se expressa no corpo humano e adquire historicidade é concebido como nexo biopsíquico humano. Esse nexo manifesta-se a partir da atividade humana no trabalho e sua historicidade é apreendida pelo conceito de adaptação: "capacidade do corpo responder com plasticidade diante de condições específicas de desenvolvimento nos processos corporais, que se expressam como formas biológicas características". Essas formas características, como os processos de adaptação que ocorrem nas distintas coletividades humanas, constituem os estereótipos de adaptação ou "modos de andar a vida".

Esses processos de adaptação significam a transformação de processos biológicos e psíquicos com o desenvolvimento ou a destruição de capacidades e potencialidades. Podem ser processos fisiologicamente normais, capazes de proteger o organismo para a sobrevivência, assim como podem transformar-se em destruidores da integridade corporal. É no estudo dos grupos humanos que esses processos são revelados, não porque opõem o indivíduo (pouco) ao grupo (muitos), mas porque o grupo é visto a partir de sua inserção social, portanto, de sua história. Os processos da adaptação caracterizam os grupos sociais ao emergir do modo específico de como esses homens apropriam-se da natureza por meio de uma determinada organização social. Sendo os grupos homogêneos no interior e heterogêneos no exterior, por comparação a outro grupo, é no grupo que se caracterizam os "modos de andar a vida" e não no "indivíduo".

Para compreender o trabalho, como determinante do PSD coletivo, é necessário analisar as formas históricas que assume no capitalismo. Nessa análise, as intermediações explicitadas por Laurell; Noriega (1989): processo de valorização$\mathrm{PV}$, processo de trabalho-PT, cargas-CA e desgaste-DE permitem articular essa relação. No pólo trabalho (dando destaque ao processo de produção-PP) é evidenciado o PV e o PT e, no pólo saúde, as CA e o DE.

Assim, o trabalho realizado modo de produção capitalista, desenvolve-se com a finalidade de gerar lucro ou mais valia. O processo de geração de mais-valia é o processo de valorização do capital. Esse ocorre simultaneamente e somente pode materializar-se no momento concreto da produção de bens e serviços - processo de trabalho. Ocorrendo os processos de adaptação que são destrutivos da integridade corporal, depreende-se que existem nos processos de trabalho "elementos que interatuam dinamicamente entre si e com o corpo do trabalhador que se traduzem em desgaste" - cargas de trabalho. As transformações negativas dos processos biopsíquicos que se originam na interação com as cargas de trabalho que geram "a perda da capacidade efetiva e/ou potencial e psíquica" é definida como processo de desgaste. Esses processos de adaptação destrutivos que caracterizam os grupos sociais conformam o perfil patológico desses grupos.

Explicitamos a seguir a decomposição dessas intermediações que estruturam a relação trabalho-saúde em particular.

\subsubsection{Processo de Valorização}

A geração de mais-valia pode ocorrer de duas formas: absoluta (aumento da jornada 
ou redução do salário) e relativa (pormudanças tecnológicas ou intensificação do trabalho).

No trabalho em saúde o produto gerado é um serviço que é consumido no momento da produção e como tal não produz mais-valia diretamente mas nem por isso deixa de reproduzir a lógica produtiva. (Gonçalves, 1994). Ao produzir um efeito útil que é consumido no mesmo momento, toma a forma de uma mercadoria e um valor a ser comercializado.

\subsubsection{Processo de Trabalho}

O trabalho é concebido como uma atividade em que o trabalhador orientado por uma finalidade, transforma um determinado objeto de trabalho em um produto final, utilizando meios e instrumentos, sob determinada organização e divisão. (Marx, 1988).

O trabalho em saúde como um serviço prestado, conforme concebido por Gonçalves (1994) desenvolveu-se no capitalismo com a finalidade de controlar as doenças em escala social e recuperar a força de trabalho incapacitada, isto pelo significado que os corpos humanos adquirem como sede da força de trabalho, precisando estar rígida para poder ser vendida e consumida. Toma como objeto o corpo humano investido socialmente nas dimensões individual e coletiva. Para a transformação desse objeto utiliza meios e instrumentos: força de trabalho em saúde (trabalho coletivo), saber, materiais específicos, equipamentos de diagnóstico e terapêutica e o local de trabalho com destaque ao hospital. As formas de organização e divisão adotadas no trabalho em saúde subordinam-se a dois modelos abstratos e complementares: clínico e epidemiológico.

O trabalho de enfermagem insere-se no trabalho coletivo em saúde, como subsidiário e complementar. (Castellanos, 1989). Diante da mesma finalidade, transforma o mesmo objeto, particularizando-se pelos meios e instrumentos que emprega (força de trabalho, saber, local de trabalho e instrumentos específicos) e pelas formas específicas de organização e divisão (divisão por categorias com qualificações diferenciadas e processos de trabalho também diferenciados entre assistir e gerenciar).

\subsubsection{Cargas de Trabalho}

Para apreendê-las é necessário decompor o trabalho em seus elementos básicos. (Laurell; Noriega, 1989).

Ao transformar o objeto no processo de trabalho de enfermagem, o trabalhador interage com a sua natureza, ou seja, os corpos individuais/coletivos e doentes dos pacientes/clientes são tomados em sua natureza biológica/psíquica como determinante do PSD desses trabalhadores. Na interação com os meios e instrumentos, a sofisticação técnica destes e as relações sociais que determinam a maneira específica de trabalhar, são geradoras das cargas. O hospital é relacionado a local de doença e morte, ao qual se associa o risco de contrair essas doenças e sofrer desgaste emocional. Na interação com as formas de organização/divisão do trabalho propriamente dito, o trabalhador expõe-se pelas diferentes formas de consumo da força de trabalho, que implicam em distintas formas de desgastar-se, 
vinculadas à extração de mais-valia, principalmente relativa, pelo aumento da produtividade.

Com isso, distingue-se dois tipos de cargas. As cargas de materialidade externa, representadas pelas cargas biológicas, físicas, químicas e mecânicas. (Laurell; Noriega, 1989, Silva, 1989). As cargas de materialidade interna constituem as cargas fisiológicas e psíquicas. (Laurell; Noriega, 1989, Silva, 1989).

\subsubsection{Desgaste}

A exposição dos trabalhadores de enfermagem às cargas gera processos de desgaste particulares (como processos de adaptação destrutivos da integridade corporal biopsíquica). (Laurell; Noriega, 1989). O processo de desgaste não se refere somente a processos irreversíveis já que é possível recuperar as perdas da capacidade efetiva e desenvolver potencialidades antes hipotrofiadas. Podem não se expressar em uma patologia específica. Assim, alguns indicadores globais vêm sendo mais freqüentemente utilizados para o reconhecimento do desgaste de determinado grupo de trabalhadores como: sinais e sintomas inespecíficos, perfil de morbidade, anos de vida útil perdidos, envelhecimento acelerado e morte prematura. (Laurell; Noriega, 1989). No trabalho de enfermagem esses indicadores não têm sido captados, tornando menos visível o processo de desgaste a que os trabalhadores são submetidos.

O desgaste deve ser considerado juntamente com os processos reprodutivos. A sua combinação com esses processos determinam a constituição característica de doenças particulares conhecido como perfil patológico desse grupo social. (Laurell; Noriega, 1989).

\section{A CONSTRUÇÃO DO ESTUDO DA RELAÇÃO TRABALHO-SAÚDE DOS TRABALHADORES DE ENFERMAGEM DO HU-USP.}

Ao estudo dessa relação está implícito um caminho metodológico orientador. Nesse caminho, buscou-se reproduzir a sistematização teórico-metodológica construída por Laurell; Noriega (1989), com os devidos ajustes para a realidade em estudo.

O presente estudo contempla uma abordagem quanti-qualitativa, utilizando várias técnicas de apreensão dos dados que constituem a triangulação de dados e permitem a comparação e validação da informação gerada.

O conceito “processo de produção" foi operacionalizado em suas 2 vertentes: PV e PT. Para a operacionalização do PV, os dados foram extraídos de várias fontes de registro referentes à universidade, ao HU e ao Departamento de Enfermagem. Permitiram apreender a lógica do processo produtivo na qual o HU está inserido e a evolução quantitativa das atividades realizadas ( $\mathrm{n}$ - de leitos, composição numérica da força e trabalho de enfermagem por categorias e a evolução quantitativa no período de 4 anos (1990/94). O PT foi decomposto enquanto processo técnico e social em seus elementos constituintes: objeto, produto final, meios/instrumentos e organização/divisão do trabalho de enfermagem. Os dados foram apreendidos pela enquete coletiva e complementada por informações dos 
enfermeiros. Assim, o PT foi decomposto/recomposto segundo a abstração da pesquisadora, fundamentada na concepção do trabalho coletivo em saúde.

Para a operacionalização do conceito "cargas", os dados foram captados basicamente pela enquete coletiva. A enquete foi construída com base no modelo proposto por (Laurell; Noriega, 1989), que tem suas origens no Modelo Operacional Italiano (Oddone, 1986) e especificada para o trabalho de enfermagem. Para sua aplicação foi formado um grupo homogêneo-GH (semelhantes processos de trabalho e atividades, condições de trabalho e riscos e problemática de saúde). O grupo foi composto com 15 trabalhadores, sendo 4 enfermeiras, 4 técnicos, 3 auxiliares e 3 atendentes. Com a informação gerada nesse grupo, foram elaborados mapas de risco das unidades nele representadas.

O conceito "desgaste" foi apreendido a partir da enquete coletiva e de outros procedimentos complementares, segundo três formas ou vertentes pelas quais se expressa. Com os dados da enquete coletiva foi reconstruída a morbidade referida. Com os dados dos prontuários dos trabalhadores encaminhados para exame médico em 1993, foi reconstruída a morbidade registrada. Com os registros de acidentes de trabalho, no ano de 1993, foram reconstruídos os acidentes de trabalho.

\section{A EXPRESSÃO DA RELAÇÃO TRABALHO-SAÚDE NOS TRABALHADORES DE ENFERMAGEM DO HU-USP}

\subsection{A PRODUÇÃO EM SAÚDE NO HU-USP}

O HU, enquanto prestador de serviço de saúde, está inserido em uma instituição formadora. Também está integrado ao SUS como hospital de referência. Nessa inserção, atende as comunidades: Butantã, USP e de pacientes de convênios e particulares. (Tolosa, 1994).

Os trabalhadores de enfermagem estão inseridos no Departamento de Enfermagem, que é subordinado à superintendência. Nessa inserção, não está favorecida a participação dos trabalhadores na representatividade frente aos órgãos decisórios, no processo decisório propriamente dito e na concepção do trabalho que realizam.

\subsubsection{O Processo de Valorização}

A expressão da produtividade do trabalho de enfermagem foi apreendida pelo incremento significativo verificado em 8 das 11 atividades eleitas para essa análise. O número de consultas de enfermagem teve o maior incremento no período (125\%) e o número de materiais processados foi a atividade de menor incremento(-29\%), possivelmente pelo uso de materiais descartáveis. O número real de leitos, aumentou em cerca de 17\%. Assim, resgatou-se que houve um incremento para a maioria das atividades desenvolvidas, ao que corresponde um impacto nas atividades de enfermagem. Isso evidencia o aumento da produtividade do trabalho de enfermagem. 
A expressão da intensificação do trabalho de enfermagem foi apreendida pela análise dos dados empíricos sobre o gerenciamento da força de trabalho de enfermagem, pela composição da força de trabalho e pela rotatividade.

Em relação à composição da força de trabalho, houve uma defasagem de 11 a $17 \%$ entre o quadro de pessoal de enfermagem autorizado e o realmente existente no período e a diminuição da proporção entre trabalhadores de enfermagem e o total de trabalhadores de $40 \%$ para $37 \%$. Isso evidencia que ocorreu um ajuste que reduziu o número de trabalhadores que poderiam ter sido admitidos caso se mantivesse o quadro autorizado para 1990. Os trabalhadores de enfermagem representaram, no período em estudo, cerca de $37 \%$ da força de trabalho da instituição, o que é considerada uma baixa proporção. Segundo dados da AMS92 (BRASIL, 1994), considerando todos estabelecimentos de saúde do País, essa proporção é de 43,67\%. No hospital, espera-se que essa porcentagem seja significativamente maior, pela necessidade de cuidado às $24 \mathrm{~h}$ do dia. Foi, também, verificado um incremento de $5 \%$ da força de trabalho de enfermagem, que não pareceu significativo para o incremento das atividades no período na totalidade das unidades.

Quanto à rotatividade, os índices são mascarados pelos trabalhadores admitidos. O número de desligamentos em 1993 representou uma média de $12,91 \%$. Os enfermeiros foram os que mais saíram da Instituição (cerca de $24 \%$ ), seguidos dos auxiliares (19\%). Os motivos citados foram o baixo salário e insatisfação pelas condições de trabalho. Os repetidos processos seletivos de alto custo, o tempo decorrido até a reposição do trabalhador devido ao tempo necessário para seu preparo, representam um desgaste para os trabalhadores que permaneceram na Instituição. A alta rotatividade também não favorece a visualização de problemas de saúde relacionados com o trabalho, que implicam em um "efeito sadio" dos que permanecem e a articulação de resistências coletivas.

Assim, evidencia-se que houve incremento quantitativo das atividades sem o incremento correspondente da força de trabalho, ocorrendo a intensificação do ritmo de trabalho, como estratégia para dar conta do incremento dessa produtividade.

\subsubsection{O Processo de Trabalho de Enfermagem}

O trabalho de enfermagem é resgatado do processo assistir do $\mathrm{HU}$ em sua especificidade e decomposto em seus elementos básicos: objeto/produto final, meios/instrumentos e organização/divisão.

Em relação ao objeto/produto final, é evidenciado que, por estar inserido no processo assistencial do $\mathrm{HU}$, o trabalhador de enfermagem transforma o mesmo objeto, com a mesma finalidade do trabalho coletivo do HU. A transformação desse objeto (corpo individual dos pacientes/clientes com demandas assistenciais no PSD). Inicia-se com a entrada desse paciente/cliente no Ambulatório ou Pronto Atendimento e daí para uma unidade de internação. Nas unidades, as intervenções de enfermagem são realizadas segundo as necessidades de transformação do PSD do paciente. Assim, o objeto e o produto final ocupam o mesmo espaço: o corpo do paciente/cliente. No centro de material e esterilização, o objeto é diferenciado e material e a finalidade do trabalho aír realizado éinstrumentalizar processos assistenciais, 
servindo à manutenção do processo assistir no HU. A característica de alguma interdependência entre as unidades pode favorecer a intensificação do trabalho nas unidades que se interrelacionam, de forma simultânea ou conseqüentemente. $A$ força de trabalho de enfermagem permitindo a continuidade do processo assistencial, evidencia a complementaridade e interdependência desse trabalho articulando às demais práticas.

Os meios/instrumentos caracterizam um trabalho predominantemente manual. O trabalhador detém um controle relativo dos instrumentos, o que possibilita tomar decisões de pequena complexidade. Geralmente, os instrumentos não são tecnologicamente avançados e viabilizam a intensificação do trabalho. O saber, que permite a apreensão do objeto e a projeção de sua transformação é diferenciado por categorias.

Nas formas de organização e divisão, resgata-se a dependência e complementaridade do trabalho de enfermagem da prática médica, reproduzindo o modelo clínico curativo e individual. As intervenções são sistematizadas pelo SAE que se converte em instrumento de controle do enfermeiro, pelo qual formaliza a parcialização das atividades. O controle é efetivado pela supervisão (voltada para o conteúdo das tarefas em detrimento do pólo educativo/orientador) pela qual se reproduz o poder institucional. Os modelos de organização e divisão do trabalho com gênese no taylorismo, fordismo, fayolismo e burocracia fundamentam a parcialização das atividades e levam à desarticulação entre a concepção/ execução, supervisão/ controle, qualificação/desqualificação, à normatização e rotinização do que fazer e como fazer. Os rodízios de turno, o trabalho noturno e a falta de pausas para descanso durante a jornada dificultam a reposição da capacidade de trabalho, além de favorecer a intensificação do ritmo.

\subsection{AS CARGASDE TRABALHO DE ENFERMAGEM}

As cargas de trabalho a que estão expostos os trabalhadores de enfermagem caracterizam-se pela diversidade (biológicas, físicas, químicas, mecânicas, fisiológicas e psíquicas). Essa diversidade também está presente em todas as unidades estudadas e diferenciam pela intensidade de exposição dos trabalhadores. Freqüentemente a maioria dos trabalhadores das unidades está exposta a esse conjunto de cargas, o que evidencia que a forma de trabalhar é geradora de cargas semelhantes.

\subsubsection{Cargas Biológicas}

As cargas biológicas citadas foram: o contato com pacientes portadores de doenças infecciosas infecto-contagiosas e/ou com suas secreções, que caracterizam a interação com o objeto de trabalho, ou seja, o corpo doente; o contato com materiais contaminados (instrumentos de trabalho) e a presença de pequenos animais (barata, mosca, mosquito, formiga), que contaminam os lanches dos trabalhadores, ressaltam a inadequação dos meios de trabalho.

\subsubsection{Cargas Físicas}

Foram citadas em relação a(o): Ruído - proveniente do ar condicionado, bip's 
dos aparelhos, sons próprios dos instrumentos de trabalho (monitores, respiradores, uso de ar comprimido) e de outros serviços (aparelho de limpeza), concentração e trânsito de pessoas, paciente em estado emocional alterado, reformas; umidade exposição à chuva ao sair da unidade, transporte de material para central de gás, pisos molhados e escoamento de água por tubulações elétricas, vapor de autoclaves, entupimento de ralos; iluminação - artificial, deficiente ou excessiva (reflexos luminosos, uso de foco luminoso para alguns procedimentos, exigência de acomodação visual pela claridade); mudanças bruscas de temperatura - uso do ar condicionado, alternação calor/frio entre as salas e estações do ano (construção/ localização), falta de ventilação, situações climáticas à saída da instituição; eletricidade - choques em equipamentos elétricos e tomadas, escoamento d'água de chuva em tubulações, descarga de eletricidade estática em contato com superfície metálica e sobre o piso, risco de incêndio e explosões; radiação ionizante - exames radiológicos sem proteção adequada ou situações que favoreçam à exposição.

\subsubsection{Cargas Químicas}

A exposição às cargas químicas citadas foram relativas às substâncias químicas de um modo geral (óxido de etileno, formaldeído e glutaraldeído); às substâncias de uso medicamentoso (gases anestésicos, quimioterápicos, antibióticos, antissépticos e outros); poeiras e fumaças (retirada de gesso, ar condicionado, talco em luvas cirúrgicas e fumo passivo dos trabalhadores) e materiais de borracha (luvas).

\subsubsection{Cargas Mecânicas}

Foram relatadas em relação à(s): manipulação de perfuro-cortantes (agulhas, tesouras, bisturi); quedas (pisos encerados, escadas); agressões (pacientes confusos ou sedados, de visitantes); prensão de dedos e mãos (maca tranfer, monta carga).

\subsubsection{Cargas Fisiológicas}

São citadas em relação à(o): manipulação de peso excessivo manipulação de pacientes (obesos, dependentes, anestesiados), de torpedos de gases, galões de substâncias químicas, de portas de autoclaves, macas, cadeiras de rodas defeituosas, de materiais permanentes e uso de aventais de chumbo (mulheres e grávidas); trabalho em pé; posições inadequadas e incômodas - assumidas durante o cuidado no leito, torção de coluna ao manipular equipamentos, verificação de sinais vitais e outros procedimentos e trabalho noturno e rodízios de turno.

\subsubsection{Cargas Psíquicas}

As cargas psíquicas citadas pelos trabalhadores foram: atenção constante: (pacientes sedados, inconscientes, anestesiados e que necessitam de vigilância); supervisão estrita - (controle, falta de autonomia e criatividade e não participação na tomada de decisões); ritmo acelerado; trabalho parcelado, monótono e repetitivo (forma como o trabalho é organizado e dividido); comunicação dificultada 
(falta de tempo imposto pelo ritmo ou por proibição de superiores, dificuldade de relacionamentos, falta de reuniões e não autorização para uso do telefone durante a jornada); trabalho feminino (dupla ou tripla jornada); desarticulação de defesas coletivas; agressão psíquica (verbal de pacientes/clientes docentes e desconsideração de alguns médicos); fadiga, tensão, estresse (trabalho desgastante e pela exposição a tantas cargas); insatisfação (perda salarial, dobras de plantão e não reconhecimento do trabalho) e situações que levam ao consumo de álcool e drogas.

\subsection{O DESGASTE DOS TRABALHADORES DE ENFERMAGEM DO HU - USP}

A exposição dos trabalhadores de enfermagem a essa diversidade de cargas é geradora de processos de desgaste que não são facilmente evidenciados, dada a sua complexidade e a conseqüente dificuldade de captar suas manifestações. Como não se refere necessariamente a uma patologia específica, uma forma de captá-lo é através de sinais e sintomas. Os danos podem manifestar-se em um período de tempo variável em que se dá o processo de adaptação destrutiva. Assim, buscamos captar o processo de desgaste através de três formas: morbidade referida e registrada e acidentes registrados.

Os dados empíricos captados por essas três formas de expressão do desgaste dos trabalhadores de enfermagem do $\mathrm{HU}$, permitiram conformar um perfil de morbidade (Quadro 1), onde sobressaem-se os ferimentos pérfuro-cortantes e os problemas ósteo-músculo-articulares.

\section{CONCLUSÃO}

Assim, no referencial teórico-metodológico que sustenta o estudo, apreendemos que o processo saúde-doença vivenciado pelos trabalhadores de enfermagem do HU-USP evidencia sua subordinação ao modo de produzir da sociedade brasileira.

Nesse estudo, o momento produtivo foi abordado como preponderante na determinação do processo saúde-doença sem que, com isso, se desconsidere que são as condições de vida e trabalho que determinam o processo de desgaste dos trabalhadores.

O processo de desgaste evidenciado pelos trabalhadores de enfermagem, assim apreendido, coloca em evidência a necessidade de transformação dessa realidade. 
(5)

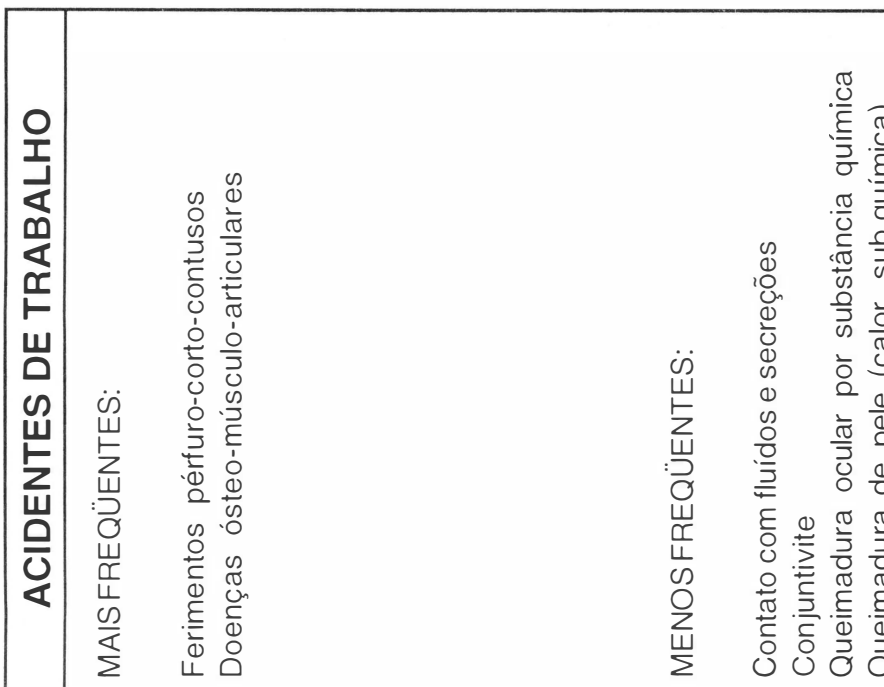

(1)

음

$\frac{E}{\sigma}$

응

气

\&

ह

ত্

है

단

$\frac{1}{0}+$

(n)

o

응

드.

ज

잔?

क ?

잉

$\frac{0}{0} \stackrel{9}{4}$

증

흔 음

ह 응

Q

产

ㄴ.

1 싱

웡

虽

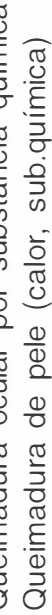
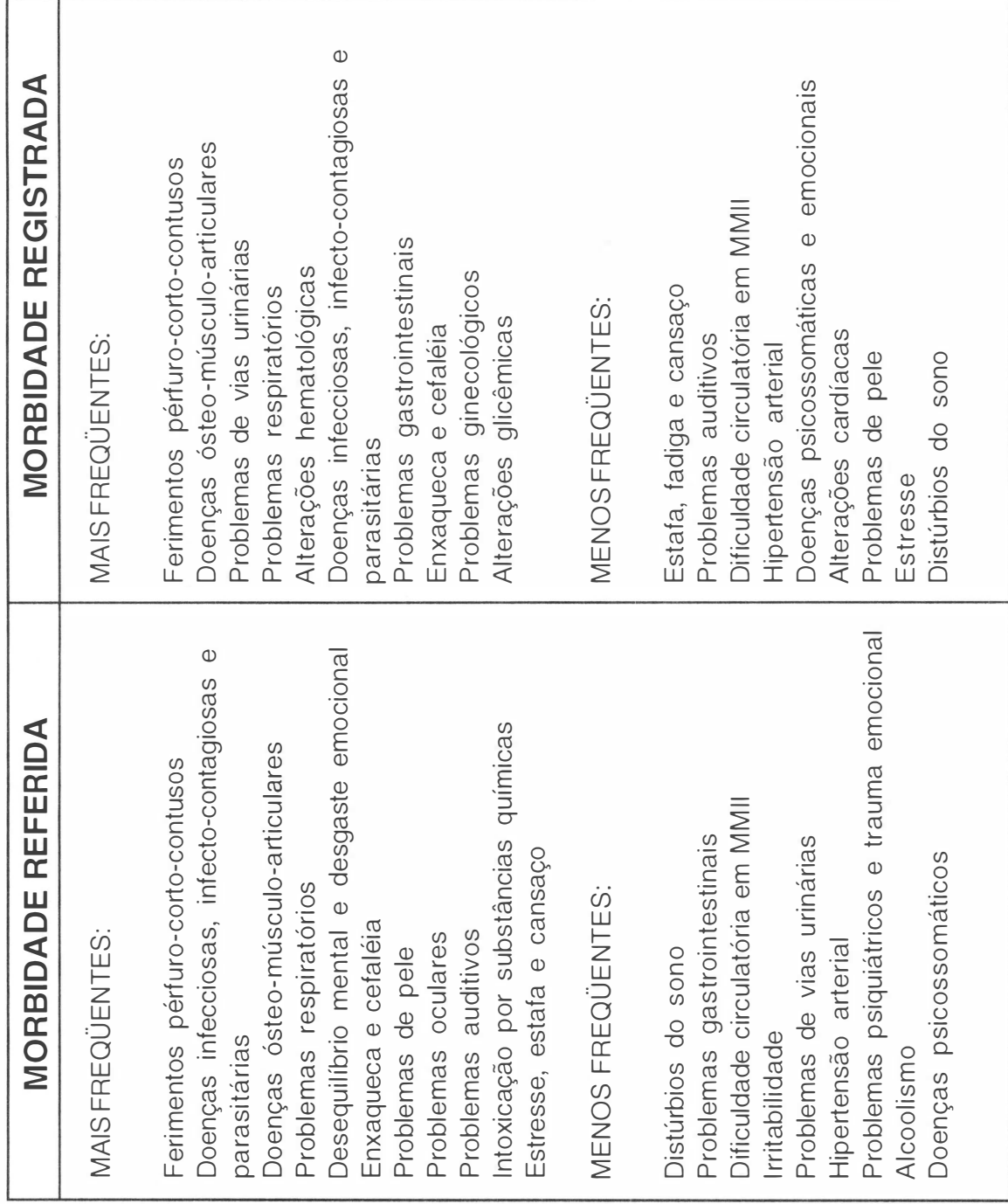

R. Bras. Enferm. Brasília, v. 51, n . 4, p. 603-614 out./dez. 1998 


\section{REFERÊNCIAS BIBLIOGRÁFICAS}

1. BRASIL. Ministério do Planejamento e Orçamento. Fundação Instituto Brasileiro de Geografia e Estatística. Estatísticas da saúde: assistência médico-sanitária AMS. 1992. Rio de Janeiro: IBGE, 1995.

2. CASTELLANOS, B.E.P. et al. Os desafios da enfermagem para os anos 90. In: CONGRESSO BRASILEIRO DE ENFERMAGEM, 41., 1989, Florianópolis. Anais... Florianópolis: ABEn, 1989. p.147-69

3. CONSELHO FEDERAL DE ENFERMAGEM. Associação Brasileira de Enfermagem. O exercício da enfermagem nas instituições de saúde do Brasil 1982/1983: enfermagem no contexto institucional. Rio de Janeiro, 1986. V.2.

4. _. Associação Brasileira de Enfermagem. O exercício da enfermagem nas instituições de saúde do Brasil 1982/1983: força de trabalho em enfermagem. Rio de Janeiro, 1986. V.1.

5. População de profissionais de enfermagem cadastrados até 31/07/95. COFEN, Brasília, 1995.Mimeografado.

6. GONÇALVES, R.B.M. Tecnologia e organização social das práticas de saúde: características tecnológicas de processo de trabalho na rede estadual de centros de saúde de São Paulo. São Paulo: HUCITEC, 1994.

7. LAURELL, A.C. La construcción teórico-metodológica de la investigación sobre la salud de los trabajadores. In: LAURELL, A.C.(Coord.) Para la investigación sobre la salud de los trabajadores. Washington: OPAS/OMS, 1993. Cap.1 p.13-35 (Série PALTEX, Salud y Sociedad $2000 \mathrm{~N}^{0} 3$ ).

8. LAURELL, A.C.;NORIEGA, M. Processo de produção e saúde: trabalho e desgaste operário. São Paulo: HUCITEC, 1989. 333p.

9. MARX, K. O capital: crítica da economia política. 3.ed. São Paulo: Nova Cultural, 1988. v.1.

10. ODDONE, I. et al. Ambiente de trabalho: a luta dos trabalhadores pela saúde. São Paulo: Hucitec, 1986.

11. QUEIROZ, V.M.;SALUM, M.J. Processo de produção de saúde./Apresentado ao Seminário de Redirecionamento da Prática da Enfermagem no SUS. São Paulo, 1994./

12. ROSA, M.T.L. da et al. O desenvolvimento técnico-científico da enfermagem: uma aproximação com instrumentos de trabalho. In: CONGRESSO BRASILEIRODE ENFERMAGEM, 41.,1989, Florianópolis. Anais... Florianópolis: ABEn, 1989. p.97-126.

13. SILVA, V.E.F. da Estudo sobre os acidentes de trabalho ocorridos com trabalhadores de enfermagem de um hospital de ensino. São Paulo, 1988. 176p. Dissertação (Mestrado) - Escola de Enfermagem, Universidade de São Paulo.

14. O desgaste do trabalhador de enfermagem: relação trabalho de enfermagem e saúde do trabalhador. São Paulo, 1996. 289p. Tese (Doutoramento) - Escola de Enfermagem, Universidade de São Paulo.

15. TOLOSA, E.M.C. et al. Hospital Universitário da Universidade de São Paulo: análise crítica dos reflexos do plano de gestão financeira-administrativa nas atividades docentes, assistenciais e de pesquisa (período de 1990-1994). Rev.Med.HU-USP, v.4, n.1/2, p.1-22, 1994. 